\title{
Editorial: Social policy implications of research in developmental psychopathology
}

\author{
DANTE CICCHETTI AND SHEREE L. TOTH \\ Mt. Hope Family Center, University of Rochester
}

In concluding his review of the historical underpinnings of the field of developmental psychopathology, Cicchetti (1990) asserted the following:

... this discipline should contribute greatly to reducing the dualisms that exist between the clinical study of and theoretical research into childhood and adult disorders, between the behavioral and biological sciences, between developmental psychology and psychopathology, and between basic and applied research. (p. 20)

In this statement, the relevance of research in developmental psychopathology to issues of critical importance to the formulation and implementation of social policy initiatives is apparent. In fact, as early as 1984 the urgent need for researchers in developmental psychopathology to conduct investigations with importance to society as a whole was noted (Cicchetti, 1984). In addition to their basic scientific endeavors, from the outset of the field developmental psychopathologists have been cognizant of the need to translate empirical research into action. From its inception, contributors to the flagship journal of the field, Development and Psychopathology,

Our work on this editorial and Special Issue was supported, in part, by a grant jointly funded by the National Institute of Mental Health and the Administration for Children, Youth, and Families (MH 45027) and by a grant from the Spunk Fund, Inc.

Address correspondence and reprint requests to: Dante Cicchetti or Sheree L. Toth, Mt. Hope Family Center, University of Rochester, 187 Edinburgh Street, Rochester, NY 14608. have been urged to consider and address social policy aspects of their research.

It has been more recently that, after 6 decades of promoting science as a means of understanding human development, the Society for Research in Child Development has begun to encourage contributors to Child Development to consider the relevance of basic research and to submit investigations that utilize knowledge to promote the welfare of children (Zigler, 1998). Whereas the journal Child Development predominantly focuses on issues pertaining to children and adolescents, the incorporation of a life span perspective by developmental psychopathologists broadens the policy relevance of research papers in Development and Psychopathology to include all developmental levels.

Historically, many examples can be found regarding the interplay among research, practice, and policy (see Zigler, 1998, for a review). In fact, the first White House Conference on Children, held in 1909, united researchers and social reformers with the goal of enhancing children's lives. Why, then, we may rightly ask, has a détente between basic research and its application to policies of public import been so long in coming? Shonkoff (2000) offers an enlightening perspective on this issue. In commenting on the formidable obstacles involved with the translation of academic knowledge to the social policy and practice arenas, he describes the "cultural" differences that accompany each of these domains. Stated simply, Shonkoff (2000) argues that scientists are trained to pose questions and to be guided by facts, whereas policymak- 
ers are governed by political and economic forces that emanate from society. Service providers are more akin to policymakers in needing to "act" before all of the data are in, so to speak. In reflecting on the tension among these groups, Shonkoff (2000) states, "Science is focused on what we do not know. Social policy and the delivery of health and human services are focused on what we should $d o "$ (p. 182, italics his). Shonkoff (2000) concludes that a commitment to "cross-cultural" translation among these three groups provides a mechanism for reconciling these differences and increasing the utilization of knowledge to improve the lives of children and families. This conclusion is consistent with that proffered by Cicchetti and Toth (1993, 1998), who advocated for a close-knit collaboration among researchers, clinicians, and policy advocates. Of course, in order for such crossdisciplinary endeavors to succeed, responsibility for increasing communication must be shared equally by all.

Perhaps one of the most egregious recent examples of the failure to consider policy implications of scientific work occurred with respect to an article published in the Psychological Bulletin on the long-term impact of child sexual abuse on college students (Rind, Tromovitch, \& Bauserman, 1998). After these findings that minimized the negative effects of sexual abuse were incorporated into the media in the spring of 1999 , a public outcry was heard that resulted in a resolution by Congress in which some suggestions in the article were condemned. A letter from Dr. Raymond Fowler, then CEO and Executive Vice President of the American Psychological Association, in which disavowal of organizational support for the opinions in the article was made attests to the furor caused by the article. Many have written about the scientific merits or problems of this investigation, and therefore we do not plan to reiterate them here (cf. Ondersma, Chaffin, \& Berliner, 1999). However, the overarching issue is the blatant failure to consider the implications of this work for society more broadly and, therefore, a naivete regarding the need for the articulation of limitations of the work for informing policy and for generalizing to all children who have been sexually abused. This unfortunate occurrence also provides a compelling example of the power of the media to respond to relevant research and may, ultimately, provide a role model for how research can reach society and have implications that surpass those of being relegated to the archives of scientific journals.

Recent initiatives by the National Institute of Mental Health, wherein funding decisions are tied to the "real world" application of research findings, certainly will encourage investigators to devise and carry out policy-relevant investigations. In a report of the National Advisory Mental Health Council on Behavioral Sciences (2000) entitled Translating Behavioral Science Into Action, strategies for enhancing contributions of behavioral science to society more broadly are proposed. The report of the workgroup concludes, "At present too few researchers are attempting to bridge across basic, clinical, and services research, and not enough are working with colleagues in related allied disciplines to move research advances out of the laboratory and into clinical care, service delivery, and policymaking" (p. v). In this report, "translational research is defined as research designed to address how basic behavioral processes inform the diagnosis, prevention, treatment, and delivery of services for mental illness, and, conversely, how knowledge of mental illness increases our understanding of basic behavioral processes" ( $p$. iii). This formulation of translational research is in direct accord with tenets of developmental psychopathology, namely the reciprocal interplay between basic and applied research, and between normal and atypical development (Cicchetti \& Toth, 1991, 1998). Moreover, Weisz and his colleagues (Weisz, Donenberg, Han, \& Weiss, 1995) have written extensively about the gap that exists between laboratory-conceived clinical services research and the transmission of empirically validated treatments into community service delivery systems.

The parameters of developmental psychopathology lend themselves to fostering research with implications for society and for policymakers. The very subject matter of the field, which encompasses risk and psycho- 
pathology, prevention and intervention, the elucidation of precipitants of mental illness, the mediating and moderating processes that contribute to or mitigate against the emergence and maintenance of psychopathology, and the incorporation of principles of normal development into the conduct of empirical investigations necessitates thinking clearly about the implications of the work and devising strategies that will remedy the problems being studied. In his discussion of normal child development, Zigler (1998) maintains that "those of us who study children must recognize that they are not merely subjects but partners in our research and we owe something to them" (p. 536). To this sentiment we add that all participants in developmental psychopathology research, whether they be infants, children and adolescents, adults with serious mental disorders such as bipolar illness and schizophrenia, or the elderly, deserve to be beneficiaries of newfound knowledge, as well as contributors to initiatives that will promote societal good.

In order to actualize the probability that research will continue to evolve in its sophistication and ability to inform social policy initiatives, increased educational initiatives will be necessary. Young investigators must be encouraged not to avoid involvement in research with policy relevance but to grapple with complex issues and to design studies from the outset that can inform policy initiatives. The development of research agendas that address normal and abnormal development across psychological and biological domains throughout the life course also is critical if policy "in the best interest" of society is to be formulated. Such well-designed and well-planned investigations are necessary to avoid unwarranted assumptions and the misuse of research information. For example, the recent embracement of "research" documenting the critical nature of the first 3 years of life for brain development, although well intentioned, greatly exaggerates the actual scientific data on which policy recommendations have been based, and actually may undermine policies for vulnerable populations (cf. Bruer, 1999; Nelson, 1999; Shonkoff, 2000). The failure to acknowledge the limitations of a given corpus of knowledge for informing policy or the actual misrepresentation of findings in order to promote a particular policy agenda reflects a gross disservice not only to public policy but also to scientific credibility and the future likelihood that empirically based information will be used to develop "best practice" standards for a variety of social ills.

With that said, we want to underscore that we are not so naive as to suggest that all policy development must await the availability of relevant data. Clearly, many societal problems are so prevalent and horrifying as to necessitate immediate action. Poverty should be reduced and adequate healthcare and nutrition made available to all children. Child maltreatment should be eliminated. High-quality childcare should be available to all families, regardless of income level. Discrimination and stigmatization, whether based on skin color, cultural background, or mental illness, must end. Issues such as these require no real data, and, certainly, action to address them must not be delayed. Conversely, however, issues such as the respective benefits of foster care versus placement with relatives, family reunification versus termination of parental rights, and when in the developmental course intervention is most effective and should therefore be most heavily funded are much less straightforward. It is with respect to areas such as these that political agendas often assume precedence and, we would argue, where the conduct of relevant research becomes paramount.

It is in the spirit of fostering dialogue among academicians, service providers, and policymakers and with the goal of continuing to reduce the schism between research and policy that the current Special Issue of Development and Psychopathology was conceived. We would be less than forthright if we minimized the challenges involved with this enterprise. Potential contributors were asked to draw from a base of research, to evaluate the utility of the work for informing social policy, and to make recommendations for how work conceived within a developmental psychopathology perspective could advance the field's understanding of issues of social import in the millennium. We also requested that, when 
available, current policies in their topic area be addressed. In fact, when we invited potential contributors we often were answered with statements such as "I can address the research in the area, but I really am not a policy person," or "There isn't anything of policy relevance in this field of research." Conversely, those with strengths in the policy arena often articulated the absence of any research with relevance to a given topic or, with some chagrin, declined participating given "their lack of knowledge" of research with policy relevance. In all of these statements, echoes of Shonkoff's (2000) "cultural differences" exposition were heard. Rather than despairing and abandoning the Special Issue, we determined that we would continue to travail this rocky road and similarly encouraged contributors to persevere and to "stretch beyond their

\section{References}

Bruer, J. T. (1999). The myth of the first three years: A new understanding of early brain development and lifelong learning. New York: Free Press.

Cicchetti, D. (1984). The emergence of a discipline. Child Development, 55, 1-7.

Cicchetti, D. (1990). An historical perspective on the discipline of developmental psychopathology. In J. Rolf, A. Masten, D. Cicchetti, K. Nuechterlein, \& S. Weintraub (Eds.), Risk and protective factors in the development of psychopathology (pp. 2-28). New York: Cambridge University Press.

Cicchetti, D., \& Toth, S. L. (1991). The making of a developmental psychopathologist. In J. Cantor, C. Spiker, \& L. Lipsitt (Eds.), Child behavior and development: Training for diversity (pp. 34-72). Norwood, NJ: Ablex.

Cicchetti, D., \& Toth, S. L. (1993). Child maltreatment research and social policy: The neglected nexus. In D. Cicchetti \& S. L. Toth (Eds.), Child abuse, child development, and social policy (pp. 1-6). Norwood, NJ: Ablex.

Cicchetti, D., \& Toth, S. L. (1998). Perspectives on research and practice in developmental psychopathology. In W. Damon (Series Ed.) \& I. Sigel \& A. Renninger (Vol. Eds.), Handbook of child psychology: comfort zones" in order to strive for a true integration of research and policy. We believe that it is only through confronting such challenges that the field will continue to move closer toward a policy-relevant research agenda. Moreover, we believe that, as a field, we also must move beyond trying to arrive at "post hoc" explanations of the relevance of research for policy and to design investigations with policy questions at the forefront. Such a priori conceptualizations will increase the value of research for society, as well as decrease the possible misinterpretation or misuse of data that were not conceived to inform policy. The 21 st century presents us all with a unique opportunity to translate rhetoric into action and to truly achieve a researchinformed policy agenda that will benefit the welfare of all.
Vol. 4. Child psychology in practice (pp. 479-583). New York: Wiley.

National Advisory Mental Health Council on Behavioral Science Workshop. (2000). Translating behavioral science into action: Report of the National Advisory Mental Health Counsel Behavioral Science Workgroup (NIH Publication No. 00-4699). Bethesda, MD: National Institutes of Mental Health.

Nelson, C. A. (1999). How important are the first 3 years of life? Applied Developmental Science, 3, 235-238.

Ondersma, S. J., Chaffin, M., \& Berliner, L. (1999). Comments on the Rind et al., meta-analysis controversy. APSAC Advisor, 12, 2-5.

Rind, B., Tromovitch, P., \& Bauserman, R. (1998). A meta-analytic examination of assumed properties of child sexual abuse using college samples. Psychological Bulletin, 124, 22-53.

Shonkoff, J. P. (2000). Science, policy, and practice. Three cultures in search of a shared mission. Child Development, 71, 181-187.

Weisz, J. R., Donenberg, G. R., Han, S. S., \& Weiss, B. (1995). Bridging the gap between laboratory and clinic in child and adolescent psychotherapy. Journal of Consulting and Clinical Psychology, 63, 688-701.

Zigler, E. (1998). A place of value for applied and policy studies. Child Development, 69, 532-542. 